\title{
The Brazilian position on forests and climate change from 1997 to 2012: from veto to proposition
}

\author{
A posição brasileira sobre as florestas e a mudança climática \\ de 1997 a 2012: do veto à proposição
}

FERNANDA VIANA DE CARVALHO*

Rev. Bras. Polit. Int. 55 (special edition): 144-169 [2012]

\section{International forest policy: institutional context}

Although there is not an international forest convention, there is a comprehensive set of international processes, non-binding instruments (soft law), institutions with a forest mandate and private regulations. Literature mentions the existence of an international forest regime (Abdalla 2007; Gulbrandsen 2004; Humphreys 2006), but the authors themselves point to its fragmentation, lack of complementarity and various inconsistencies.

I propose the concept of a quasi-regime for the protection of forests. This concept is based on the understanding that the mass of political and technical instruments, whether public or private, does not amount to a framework of principles, rules and expectations around which actors' expectations converge, as Krasner (1983) postulates in his classical definition of international regimes. I also consider that another fundamental attribute for a regime is its effectiveness (Young 1999; Sprinz 2007; Dimitrov 2005). Therefore, the sum of existing public and private institutions and instruments, binding and non-binding, directly or indirectly connected to the issue of forests, is in a stage that is inferior to the existence of an international regime. Besides its very low level of implementation and effectiveness, its lack of coordination and the absence of clear institutional mandates make it hard to map both stakeholders and expectations around which it should converge.

Although a regime does not exist, its absence is not the reality either. For Keohane and Nye (2001), such a situation means the nonexistence of agreed norms and procedures, or that the exception to the rule is more relevant than its existence. Therefore, I consider that the problematics of international forest

\footnotetext{
* Brazilian Representative at The Nature Conservancy in Brasília. LL.M. in International Environmental Law, University of Nottingham, and PhD in International Relations, University of Brasília (fcarvalho@tnc.org).
} 
policy is in an intermediate locus between the existence and nonexistence of a regime: a quasi-regime. There is minimal convergence around requirements for an international forest policy: sustainable forest management, protected areas, compatibilization between environmental protection and international trade, rights of forest peoples, among others. There is also a set of principles that is weak but brings those international arrangements close to an international regime.

The main institutions and instruments of the international forest quasiregime are the Food and Agriculture Organization of the United Nations (FAO), which had a controversial role in the 1980s, and now prioritizes financial and technical assistance through National Forest Programmes; the International Tropical Timber Organization (ITTO) and the International Tropical Timber Agreement (ITTA), which bring together producer and consumer countries to regulate the trade of tropical woods and the sustainable use of forests, although this last objective has always been secondary; the World Bank, which also had a controversial role in the 1980s and 1990s funding projects with massive impact, but later developed operational policies and procedures aimed at reducing that impact; the United Nations Forum on Forests (UNFF), connected to the Economic and Social Council (ECOSOC) with virtually global membership and responsible for the implementation of the Non-Binding Forest Principles (1992) and their developments; and the Convention on Biological Diversity (CBD), which provides a framework for conservation and sustainable use of biodiversity and the fair and equitable sharing of benefits connected to that use.

The United Nations Framework Convention on Climate Change (UNFCCC) is also part of the international forest quasi-regime and has recently become the main international forum for discussions on forests. Forests are considered sources ${ }^{1}$, sinks ${ }^{2}$, and reservoirs ${ }^{3}$ of greenhouse gases (GHG), so they are at the same time part of the problem of global warming, as they emit greenhouse gases from burning and clear-cutting, and part of the solution of the problem as they mitigate its effects through carbon storage, removing $\mathrm{CO}_{2}$ from the atmosphere and keeping it in their biomass while they grow.

Data from the $4^{\text {th }}$ Assessment Report of the IPCC (2007) estimate that $\mathrm{CO}_{2}$ emissions from deforestation and land-use change amount to $17 \%$ of global emissions. So the forest sector is the third largest emission source, behind the energy (26\%) and industry (19\%) sectors and followed by the agriculture (14\%) and transportation (13\%) sectors. The multiple role of forests is a very complex and disputed issue in the negotiations on climate change since the preparatory

\footnotetext{
1 Source: any process or activity which releases a greenhouse gas, an aerosol or a precursor of a greenhouse gas into the atmosphere (UNFCCC, Art. 1.9).

2 Sink: any process, activity or mechanism which removes a greenhouse gas, an aerosol or a precursor of a greenhouse gas from the atmosphere (UNFCCC, Art. 1.8).

3 Reservoir: a component or components of the climate system where a greenhouse gas or a precursor of a greenhouse gas is stored (UNFCCC, Art. 1.7).
} 
meetings to the United Nations Conference on Environment and Development (UNCED) up to now. This is due to the economic valuation of those ecosystems in the context of emissions-reductions market schemes.

\section{International policy on forests and climate change: from the legal to the economic sphere}

This section focuses on the shift of the international discussion on forests from a legal perspective, connected with territorial and sovereignty issues, to an economic perspective, connected to the environmental service of carbon sequestration provided by forests.

The forest window within the climate change regime was opened right after the UNCED in 1992, where the discussions on an international forest convention ended with a weak compromise that is reflected in the name of the document adopted: Non-Legally Binding Authoritative Statement of Principles for a Global Consensus on the Management, Conservation and Sustainable Development of All Types of Forests. At that time the tone of international discussions on forests was the sovereignty of countries over their natural resources. During the negotiation process previous to the UNCED, the most disputed issues regarding the proposal of a convention on forests were the concepts of guardianship or stewardship of forest resources to guarantee the fulfillment of needs of present and future generations and common good/common heritage of mankind (Humphreys 2006).

The ultimate objective of the UNFCCC, open for ratification in UNCED, is "to achieve stabilization of greenhouse gas concentrations in the atmosphere at a level that would prevent dangerous anthropogenic interference with the climate system" (UNFCCC, Art. 2). In 1997 the Kyoto Protocol defined that this objective should be reached through reductions of GHG emissions by sources and removals by sinks resulting from direct human-induced land-use change and forestry activities, limited to afforestation, reforestation and deforestation since 1990. The position by some countries, such as Brazil, that forestry projects threatened the principle of common but differentiated responsibilities of the UNFCCC was coherent with the political discourse and views on that matter at that time.

Before Kyoto, in 1995, a pilot phase of Activities Implemented Jointly (AIJ) was defined in the UNFCCC. This phase involved the pioneer forestry projects for climate change mitigation in developing countries with investments from developed countries. As valuable lessons have been generated under the AIJ framework, the Conference of the Parties has decided they should go on indefinitely, although reductions of emissions are not considered to fulfill Kyoto commitments (Dec. 14/CP.8). The biggest investors were Sweden and the US. Under this framework there are 157 projects, 40 of which located in South America. Brazil did not host any AIJ; the country strongly opposed such activities that shifted the burden of emissions reductions by Annex I countries to developing countries. There are only 
17 forestry projects for reforestation, preservation and afforestation (UNFCCC, $7^{\text {th }}$ Synthesis Report, 2006).

In 1997, in order to reach the ultimate objective of the UNFCCC, the Kyoto Protocol established "quantified emission limitation or reduction commitments," which are targets for Annex I parties that can be reached through domestic actions and supplementary flexible mechanisms that allow cost-efficiency in reductions. The Protocol established three flexible mechanisms: joint implementation, which allows Annex I parties to jointly achieve their reduction targets based on an agreement between them that sets out the respective emission level allocated to each one; emissions trading, which allows Annex I parties to transfer to or acquire from each other emission reductions from projects aimed at reducing anthropogenic emissions by sources or enhancing anthropogenic removals by sinks of greenhouse gases; and the Clean Development Mechanism (CDM), which allows Annex I parties to invest in project activities in non-Annex I parties and use the certified emission reductions from such project activities to contribute to compliance with part of their targets (Kyoto Protocol, Articles 4 and 12).

It can be argued that Kyoto is a cap-and-trade system. Cap-and-trade was first put in place in the US in the 1990s as the result of an alliance between the government and nongovernmental organizations (NGOs) aiming at controlling the pollution caused by substances that caused acid rain (Coniff 2009). Cap-and-trade is an alternative to traditional command-and-control policies. Simply put, there is a regulating entity that establishes a cap (a maximum target of emissions) and each party or entity that is covered by the system is assigned an amount of emissions for a period. At the end of the period the covered party or entity has to demonstrate it complied with its allowed share, either through emission reductions or purchasing reductions from other parties. Kyoto established a cap (reduction of emissions of at least 5\% below 1990 levels in the commitment period of 2008 to 2012, Art. 3) and parties have specific emission reductions targets that can be achieved through a mix of alternatives, such as trading or investing in projects in developing countries. Therefore, Kyoto created a carbon market with a supplementary role to domestic measures.

It is important to highlight that the expression "carbon market" is broader than the official market under the UNFCCC. Lecocq and Ambroise (2007) define carbon market as the sum of all transactions in which one or more parties pay each other or a set of parties for a certain amount of emission reduction credits. Those credits theoretically represent real emission reductions, which could be used by countries in reaching their Kyoto targets or by industries to comply with national legislations, or even as voluntary reductions for corporate responsibility or public-relations purposes. Those reductions are called offsets.

One of the flexible mechanisms described above, the Clean Development Mechanism (CDM) is the only one that allows for the participation of developing countries (or non-Annex I parties). It aims at helping those countries to achieve 
sustainable development and Annex I parties to comply with their quantified emission reduction commitments, therefore contributing to the ultimate objective of the Convention. Its rationale is that non-Annex I parties will benefit from projects financed by Annex I parties that will result in certified emission reductions (CER), the so-called carbon credits, which can be used by Annex I parties to fulfill part of their commitments. Afforestation ${ }^{4}$ and reforestation ${ }^{5}$ are the only eligible forestry CDM project activities.

It is relevant to notice that few forestry projects have been approved under the CDM. As of August 2012, there are only 39 afforestation and reforestation projects out of 4,396 projects registered by the CDM Executive Board (CDM Registry 2012). Some factors that could explain this is the low international demand for forest credits; the high complexity of technical requirements; high transaction costs with low profits; and the fact that forest credits are temporary ${ }^{6}$.

The role of flexible mechanisms in the climate change regime brings up a broader discussion on equity, justice and the environmental integrity of the climate change regime. The principle of common but differentiated responsibilities and respective capabilities implies that Annex I countries should take the first step in emission reductions in their territory. Besides that, they should financially contribute and transfer technology to allow developing countries to fulfill their commitments under the UNFCCC. There are equity and justice issues if those mechanisms actually mean shifting the burden of mitigation to developing countries. The environmental integrity of the regime will be threatened if the use of offsets is unlimited, which could delay domestic efforts to reduce emissions that would keep on increasing. That would be a zero-sum game for the global climate: countries would gain time to invest in technology and to introduce emission cuts, but the global warming threat would intensify and demand even stronger interventions and investments.

Brunnengraber (2007) divides the international policy of climate change in two phases. The first one is up to 1997, when the issues on the table were the equitable discussion of per capita emissions, the connection between poverty, wealth and environmental degradation, historical responsibility for climate change and the need of transferring substantial funds from developed to developing

4 Afforestation: the direct human-induced conversion of land that has not been forested for a period of at least 50 years to forested land through planting, seeding and/or the human-induced promotion of natural seed sources (Decision 16 CMP 1, Art. 1.1.b).

5 Reforestation: is the direct human-induced conversion of non-forested land to forested land through planting, seeding and/or the human-induced promotion of natural seed sources, on land that was forested but that has been converted to non-forested land (Decision 16 CMP 1, Art. 1.1.c).

6 After long discussions on permanence of forestry projects, it was defined that certified emission reductions for such projects under the CDM would be temporary. A tCER is a temporary certified emission reduction issued for an afforestation or reforestation project activity under the CDM which expires at the end of the commitment period following the one during which it was issued. A ICER is a long-term certified emission reduction issued for an afforestation or reforestation project activity under the CDM which expires at the end of the crediting period of the afforestation or reforestation project activity under the CDM for which it was issued (Dec. 19 COP-9). 
countries. The second phase starts with the adoption of the Kyoto Protocol in 1997, when the focus was narrowed to economic matters due to the fact that the fossil fuel industry noticed the relevance or the threat of that instrument to its interests. Economic measures, new technologies and financial instruments are the issues that dominate negotiations.

The valuation of the economic service of carbon storage provided by forests, with its inherent political, technical and economic complexities, has become a more relevant discussion in the international arena than other aspects of the forest problematics such as rights of indigenous peoples, protected areas and international drivers of deforestation. A recent phenomenon is the connection of such issues to the Reducing Emissions from Deforestation and Forest Degradation programme $(\mathrm{REDD}+)^{7}$ discussions in the UNFCCC.

\section{REDD+: UNFCCC as a "Forest Convention"?}

Since 2004 a group of Brazilian and international NGOs started to manifest their support to a mechanism that could compensate tropical forest countries for reducing deforestation. In 2005 a group of countries led by Papua New Guinea made a submission to the UNFCCC for the inclusion of this proposal in the agenda of the next Conference of the Parties (COP-12, in Nairobi). This proposal, which was supported by Brazil, was accepted by the COP. Brazil would present its own proposal in 2006. In 2007, at COP-13, in Bali, REDD+ was included in the Bali Action Plan, the decision that opened the negotiations for a new period of the climate change regime after 2012. Those negotiations were supposed to come to term in 2009, in Copenhagen, which did not happen. In 2011, in Durban, the COP defined a new mandate for negotiations up to 2015 for an agreement including developed and developing countries to be adopted in 2020.

From 2005 onwards the discussion on REDD+ has become polarized. A first position, defended by Brazil, is that it should be financed by public funds and not a market mechanism to maintain the environmental integrity of the mitigation system. The opponent position is that REDD+ should be included in a market mechanism to generate offsets, which is defended by the Coalition for Rainforest Nations, a group within the G-77 that includes Papua New Guinea, Costa Rica and other countries that signed the submission in 2005. Brazil is not a part of this group.

The discussion on REDD+ has also become much more complex since 2005. Issues on the table are how to involve countries with different scientific

7 According to the Bali Action Plan (Decision 1 COP-13), REDD+ is defined as policy approaches and positive incentives on issues relating to reducing emissions from deforestation and forest degradation in developing countries; and the role of conservation, sustainable management of forests and enhancement of forest carbon stocks in developing countries. Since 2005, based on a submission by Papua New Guinea, Costa Rica and other countries, this issue that was excluded from the Kyoto Protocol came back to the UNFCCC negotiations. 
and technical capacities; how to tackle the various drivers of deforestation in each country or region; how to connect benefits at the local level and emissions reductions at the local level; how to make REDD+ contribute to poverty reduction and the conservation of other natural resources such as biodiversity, water and soils; how to guarantee that local communities and indigenous peoples can benefit from such a mechanism. In $2009 \mathrm{REDD}+$ went through passionate debates that reflected the diversity of views among countries on how to deal with it. The main points of discussion were the following:

1. Scope of the mechanism: the inclusion of other activities mentioned in the Bali Action Plan besides reducing deforestation, and degradation, i.e. conservation, enhancement of stocks, and sustainable forest management. Some countries question the inclusion of activities that do not directly reduce emissions. On the other side are countries with low deforestation rates and high forest stocks, for whom a mechanism that rewards only countries with high deforestation rates could create perverse incentives and foster unsustainable activities. In Copenhagen a consensus that the mechanism should include all activities mentioned in the Bali Action Plan should be considered under a REDD+ framework.

2. Co-benefits: REDD+ projects, programs or strategies should generate other benefits besides reducing emissions, such as maintaining and improving other environmental services.

3. Avoiding conversion of native forests: REDD+ projects or strategies should not become an incentive for converting native forests to monocultures of exotic species of rapid growth which could be more efficient in removing $\mathrm{CO}_{2}$ from the atmosphere.

4. Rights of indigenous peoples and local communities: this is one of the hottest issues on REDD+ discussion, given the demand by Indigenous Peoples representatives that countries acknowledge the United Nations Declaration on Rights of Indigenous Peoples (UNDRIP). However, this declaration is a non-binding document that has not yet been signed by the United States. The US, however, accepted a formulation that mentioned "taking note" of the UNDRIP. The rights that should be considered are territorial rights; full participation; free, prior and informed consent; and equitable benefit sharing.

5. REDD+ as a nationally-appropriated mitigation action (NAMA): views diverge on the role of REDD+ in the international climate regime. One option is that REDD+ initiatives could generate emission reductions to be converted in carbon credits/offsets which could be used by developed countries to compensate emissions from sources. Other option defended by Brazil is to consider REDD+ a NAMA, which would be part of the voluntary domestic actions of developing countries with the financial 
and technological support from developed countries, therefore not generating offsets.

6. Finance: the main contentious issue on REDD+ discussions, as already mentioned, is the kind of financial resources that should maintain such a mechanism. For Brazil, including REDD+ in a market mechanism threatens the environmental integrity of the regime as issues of permanence and leakage have not yet been solved. For the Coalition for Rainforest Nations, a carbon market is predictable, robust and stable and therefore is the safest financial mechanism. This view is supported by developed countries which are interested in cost-effective emission reductions options, such as the USA and Norway. The European Union is against a carbon market for REDD+ and even CDM forest credits are not allowed in the EU Emissions Trading Scheme (ETS), but it has not proposed alternative mechanisms or pledged significant additional public funds for REDD+.

Considering the variety of issues presently at stake on the construction of a REDD+ mechanism under the UNFCCC, it can be argued that the Convention is expected to solve many gaps that remain unsolved in other instruments of the quasi-regime on forests, such as Indigenous Peoples' and local communities' forest tenure rights and the conservation of natural resources other than forests under the co-benefits. It is necessary to go back to the ultimate objective of the Convention, which is reducing anthropogenic emissions of greenhouse gases, and to also consider who the country representatives are and their capacity and mandate to deal with such issues. In a world constrained by a financial crisis, it seems natural that claims will migrate to where the financial resources and the political relevance in the international agenda are located. But will the UNFCCC be able to deal with such a broad array of issues? The answer to this question remains unknown and unlikely in the near future, as even the commitments of domestic emission reductions which form the core of the climate change regime have not yet been renewed.

Bäckstrand and Lövbrand (2006) identify three global environmental governance discourses on the sinks discussion in the UNFCCC: ecological modernization, green governance, and civic environmentalism. Ecological modernization focuses on the compatibility between economic growth and environmental protection, liberal market capitalism and sustainable development. Cost-effective solutions are preferred over fair and equitable ones. The green governability discourse is based on a notion of technical and scientific tutorship of nature and the complete management of its resources. The experts and scientists that migrated to the environmental policy arena in the last decades have a relevant role in the construction of such ecological knowledge. The manifestation of this 
discourse is prominent on climate change discussions and it is considered elitist as it marginalizes other types of understanding of the natural world. Finally, the civic environmentalism discourse is associated with Rio 92, when the language on stakeholders' participation entered the international environmental agenda. While the principle of sovereignty and the privilege of States as the sole decision-makers in international negotiations remain, the participation of other groups and nonstate actors such as the business sector and NGOs has created more complex and polycentric governance arrangements.

All three discourses can be identified in the discussion on forests in the UNFCCC. When the carbon market was created, the predominant one was ecological modernization, since the rationale of the market is flexibility and cost efficiency that minimizes the prescription of obligations and their fulfillment for ethical reasons, such as the acknowledgment of countries' contribution to the problem. Therefore, it makes sense to take into account both sources and sinks in a mitigation system. Another piece of this discourse is the narrative of "maximizing synergies," which suggests that projects involving tropical forests combine lowcost mitigation with sustainable forest management, poverty reduction, local development, and biodiversity protection (Bäckstrand and Lövbrand 2006). Green governability can be perceived in the argument that technical and scientific constraints that were present in 1997 have been solved. And for countries which are against REDD+ in a market mechanism that would allow for offsets, civic environmentalism is a great ally: rights of forest peoples, which are legitimate stakeholders in the discussion, are threatened by a REDD+ mechanism.

\section{The Brazilian position on forests and climate change: from veto to proposition}

The positions of States in international environmental negotiations stem from a balance between external pressure and political and economic interests and forces both at the domestic and transnational levels. Risks and costs associated with environmental degradation vary across themes and countries involved, as do incentives for participation in regimes. Solutions for the problems at stake are also perceived differently by actors. Therefore, reaching consensus is a slow and challenging exercise.

Chasek, Downie and Brown (2006) highlight the importance of veto power as one of the main characteristics of global environmental policy. For each issue there is a country or a group of countries whose cooperation is so essential for an agreement to succeed that this country or group could block efficient international action. When those countries oppose or try to dilute an agreement for any reason, they act either individually as veto states or collectively, forming veto coalitions. Veto power is so relevant that even more economically powerful countries have 
no means to impose an international agreement on poorer countries if those, for specific reasons, are fundamental to an agreement and oppose it. Some examples are the coalition formed by Brazil, Indonesia, Gabon, and Malaysia on Rio 92 to block an international convention on forests and the Like-Minded Megadiverse Countries (LMMC) in the Convention for Biological Diversity. Veto power can also be used as a currency for compensation or more favorable treatment. Within the UNFCCC, as decisions are taken by consensus, theoretically every country could veto decisions, but reality is more complex. There are political and economic asymmetries which qualify countries' veto power.

For the analysis of the Brazilian position on forests in the climate change regime, two distinct phases were identified. The first one is from 1997 to 2005. In the big picture of climate change negotiations, Brazil has been considered a leader of the G-77 and China - the coalition of developing countries - for its strong position of fighting for the adoption of quantified emission reduction commitments by developed countries and the attribution of appropriate commitments for developing countries, based on the principle of common but differentiated responsibilities, which would not curb their right to development. However, on the specific issue of forests and climate change, in this first phase Brazil strongly resisted discussing mitigation measures related to emissions from tropical deforestation and degradation, using the argument of sovereignty over natural resources as a shelter. That positioned Brazil as a veto state, opposed to the USA and even countries in the G-77 and China, such as Costa Rica and Colombia.

The veto power of Brazil on the forest issue in the international climate regime lies on the following factors:

1. Brazil possesses the largest area of tropical forests in the world. About $64 \%$ of its territory (about 544 million hectares) is covered by forests (FAO 2010).

2. Brazilian GHG emissions differ from other countries' profiles due to the large share of hydropower in its energetic matrix and the relevance of deforestation and degradation as emission sources.

3. Brazil significantly diminished its deforestation rates from 2005 to 2012 , achieving a reduction of $65 \%$ since 2004 .

4. Brazilian negotiators have high technical capacity (La Viña, personal communication, 2010).

Friberg (2009) considers that Brazil has a proactive and influential role in the UNFCCC. He describes the Brazilian position as complex and composed by three lines: responsibility based on the historical contribution of countries to the problem of climate change; financing for clean development; and engagement on discussions on forests and the forestry sector. The last line is the one where Brazil has most efficiently exercised its veto power, backed by the argument of the lack 
of technical and scientific certainty and methodologies on specific issues such as monitoring and carbon accounting. But for Viola (2004), nationalist values of a relevant share of the national bureaucracy (the military and institutions responsible for international relations and promoting development) shaped positions in the 1990s. Therefore, any international interest related to the Amazon was seen as a threat to Brazilian sovereignty. It can be then concluded that what really defined the Brazilian position from 1997 to 2005 were principles and political views, while solid and coherent technical and scientific arguments were presented. Brazil used this strategy to effectively oppose the inclusion of native forests in the Kyoto arrangement of sources and sinks.

Although Brazil can be classified as a leader in the international climate change agenda, its position from 2005 to 2012 cannot be explained by any of the categories proposed by Chasek, Downie and Brown (2006) ${ }^{8}$. Brazil cannot be considered a leader in the issue of forests and climate change for a number of reasons. The first is that its position on forests has not become the leading one among the forest countries in the G-77 and China, most of which have adhered to the marketfriendly position led by Papua New Guinea and Costa Rica. The second is the fact that while Brazil has always demanded that resources should flow from developed to developing countries for climate change mitigation, the country has accomplished the huge effort of reducing deforestation with its own national budget. It seems that Brazil has tacitly adopted the position that international funds from the climate change regime were not needed for controlling deforestation. Therefore, countries interested in those funds and countries interested in purchasing such reductions of emissions in a market mechanism had the opportunity to strengthen their position in negotiations.

However, strategic developments took place nationally in Brazil that, although not connected to the UNFCCC, granted the country an influential position in negotiations regarding forests. So for the purposes of this article the Brazilian position is considered to have evolved from a simple veto to the proposition of alternatives. The subtle transition from not allowing discussions to progress on an issue that Brazil was not interested in bringing to the international climate change to participating in discussions with its own proposal on the table starts in 2005. The landmark is the submission to the UNFCCC of a proposal of creation of an international fund to revert forest destruction through "positive incentives for reducing deforestation." Such proposal has not become the preferred approach for tropical forest countries, which have moved closer to the proposal by Papua New Guinea, Costa Rica and other countries of considering native forests in an offset market mechanism. However, the fact that Brazil is an influent country that does not agree with offsets has forced the continuity and evolution of negotiations.

8 Leader state, supporting state, swing state, and veto state. 
It is important to mention again that in the UNFCCC decisions are taken by consensus. It would be therefore legitimate for Brazil to maintain its veto position regarding the inclusion of native forests in the regime as it effectively did from 1997 to 2005. But the country has opted for a constructive and more sophisticated conciliating position, which allows it to pursue common ground, influence countries, and build convergent points of view on specific issues of the discussion with the Coalition for Rainforest Nations, its opponent.

In 2007 another important development took place. Brazil, together with China and South Africa, announced its willingness to adopt voluntary commitments later referred to as "nationally-appropriated mitigation actions" (NAMAs). This willingness later materialized in domestic strategies, such as the National Climate Change, which introduced for the first time a target for deforestation reduction in the Amazon ( $80 \%$ by 2020). The creation of the Amazon Fund from an arrangement with Norway that built on a proposal by Brazilian NGOs with the support of Norwegian counterparts has also become a pillar of the Brazilian position in the Convention.

The year of 2009, which culminated with the unsuccessful COP-15 in Copenhagen, was specially determinant for the Brazilian position. Brazil advanced on the adoption of national voluntary commitments to reduce emissions of $36.1 \%$ to $38.9 \%$ from business-as-usual by 2020 , of which reducing deforestation is a central strategy. That move has significantly strengthened Brazil's soft power in the UNFCCC. A new informal coalition, the one formed by Brazil, South Africa, India and China (BASIC), has emerged in Copenhagen and was fundamental in negotiating the Copenhagen Accord. The relevance of the BASIC has been growing as it encompasses the emerging countries with growing emissions that some Annex I countries would like to see taking on commitments within the climate change regime. Although the international arena mapped here was somewhat important, I argue on the next session that domestic factors were the main reason for the change in the Brazilian position.

\section{Brazilian domestic framework from 2003 to 2012}

For Putnan (1988), questioning whether it is domestic policy that influences international policy or otherwise is not so relevant, as the answer is that both influence each other in specific moments. "When" and "how" that happens are more interesting theoretical questions. For Allison (1971), international policy positions result from the sum of internal bargaining games (bureaucratic politics model). Assuming that the transition of Brazil from veto to proposition is influenced by the domestic political framework from processes that started in 2003, this session aims at describing such dynamics which can only be explained by the sum of multiple, complementary, and non-hierarchical variables. 


\section{The emergence of the Ministry of the Environment as a relevant player in climate change negotiations}

Within the Federal Government, the institutional players that built the international position on forests and climate change from 1997 to 2012 are the Ministry of External Relations - Ministério das Relaçôes Exteriores (MRE) -, the Ministry of the Environment - Ministério do Meio Ambiente (MMA) -, and the Ministry of Science and Technology - Ministério da Ciência e Tecnologia (MCT). The evolution in this position reflects a shift in the power of those players in the policymaking game since 2005: MMA strengthened and qualified its presence, with the support of the President, civil society, state governors from the Amazon region, and the private sector.

According to Brazilian law, the MRE has the mandate of participating in international negotiations and assisting the President on international policymaking. The MCT presides the Interministerial Commission on Global Climate Change, whose mission is to articulate governmental action on that matter. Therefore, this ministry is the main sectoral institution on international climate change discussions. The MMA is entitled with the national environmental policy and the preservation, conservation, and sustainable use of ecosystems, biodiversity, and forests, and it is the vice-president of the aforementioned Interministerial Commission on Global Climate Change. Another political body on climate change, created in 2007, is the Interministerial Committee on Climate Change, whose main attribution is elaborating and implementing the National Climate Change Plan.

Differently from the Commission, the Committee is presided by the Civil House of the Presidency, which shows that the topic has shifted from a technical and scientific perspective to a strategic one connected to development policies, therefore acquiring political relevance in the presidential agenda. The Civil House of the Presidency has been more active in the domestic sphere than in the international one, but its participation in international negotiations is growing and it has been particularly important in settling disputes among the three ministries involved.

The position of MRE and MCT can be described as conservative. Those ministries consider that market mechanisms have inherent uncertainties: it is hard to measure, report and verify emissions reductions, and there are threats of fraud and corruption (Viola, personal communication, 2010). For those actors forest carbon should be a secondary option to reducing domestic emissions due to lack of permanence and high transaction costs. Offsets should not be allowed as they threaten the environmental integrity of the regime, allowing continuous growth of emissions in Annex I countries. The MRE sees itself as a mediator of conflicts between sectoral ministries. The Civil House of the Presidency will arbitrate those conflicts whenever differences cannot be resolved (Ambassador Luiz Alberto 
Figueiredo Machado, personal communication, 2010). The MCT was the most influential sectoral institution until 2011 not only because of its legal mandate, but because its position converges with the rationale of the MRE, despite the allegedly neutral standing of the latter.

The MMA is a more recent actor in international discussions on climate change and forests, despite its mandate to build the national forest policy. This is a reflection of the previous mindset that forests were to be maintained as a national issue that should be protected from international saying. According to a representative (personal communication, 2010), in the UNFCCC the issue has evolved from a formal treatment under the mitigation package to a broader space that acknowledges its specificities, such as the impact of mitigation mechanisms on forest governance. In this context the MMA aims at integrating mitigation strategies to national forest governance. The MMA is open to the possibility of a mechanism that includes both deforestation and carbon stocks. In the case of conservation, the MMA agrees that methodological developments are needed to estimate and verify its impact on climate change mitigation. Since 2009 the MMA has defended that Brazil should participate on REDD+ international governance due to its influence and negotiating capacity to guarantee the environmental integrity of the system (Thaís Juvenal, personal communication, 2010). For the MMA the possibility of forest offsets to compensate fossil fuel emissions is "complex," which signals a more progressive view than "unacceptable."

The role of the MMA as a relevant actor in forest and climate negotiations is recent and its emergence is acknowledged by MRE and MCT. However, such emergence in the domestic game of the Brazilian position is neither simple nor pacific. Some tense moments of negotiation took place, such as the construction of the 2006 Brazilian proposal of positive incentives to reduce deforestation. The proposal required internal discussions at the MMA, meetings with civil society representatives, and discussions with the MCT and MRE. The MMA was successful in accommodating its counterparts' demands of a mechanism that was not connected to carbon markets.

The MMA has always been present in UNFCCC discussions in the Brazilian delegation, but not with high-level representatives until 2003, and not with a focus on forests until then. On COP-9, in 2003, the MMA was represented by its Executive Secretary, who has the status of Vice-Minister. In COPs 10, 11, 12 and 13, Minister Marina Silva was present and even led the Brazilian delegation in specific moments. This shows a shift in the perception of climate change by that institution. In 2006, the preliminary version of the Brazilian proposal was presented by the Secretary of Forests and Biodiversity of the MMA at a workshop in Nairobi.

Something that contributed to the MMA's qualified insertion in the international climate change agenda was the transformation of its Secretariat for Environmental Quality into a Secretariat for Environmental Quality and Climate 
Change in 2007. For the first time that Ministry had a specific institutional locus with the attribution of coordinating its actions connected to climate change and proposing policies and economic instruments to regulate the CDM. Within the Secretariat, a Climate Change Department was created with the mandate to participate and advise the Ministry in international negotiations on climate change. The first Secretary of Environmental Quality and Climate Change was Thelma Krug, who came from the MCT, a historical member of the Brazilian delegation and leading forest negotiator since 2000. This move by the MMA demonstrates its willingness to occupy a privileged space in UNFCCC discussions.

\section{Governance over deforestation and strategic domestic developments}

The Brazilian position of veto to the inclusion of forests in the climate change regime from 1997 to 2006 aimed at pushing away international scrutiny due to the high deforestation rates from 1995 to 2003. In 2003 Minister Marina Silva defined strategic directions for the MMA that involved promoting sustainable development, social participation and control, strengthening the environmental national system and "transversality," or the involvement of the different sectors of government in solving environmental problems (MMA 2006). This last direction was decisive for controlling deforestation as this became a government policy under which various ministries and the Civil House of the Presidency had roles and responsibilities.

Still in 2003 the MMA successfully proposed the creation of a Permanent Interministerial Working Group formed by 14 ministries with the aim to propose and coordinate measures to reduce deforestation rates in the Amazon. In 2004 this Working Group submitted to the President the Action Plan for the Prevention and Control of Deforestation in the Amazon - Plano de Ação para Prevenção e Controle do Desmatamento na Amazônia (PPCDAM). This plan was crucial in the significant drop of deforestation from 2005 to 2012. It can be affirmed that this plan has established the political foundations for Brazil to adopt its voluntary targets in 2009.

The plan is divided in three axes: land tenure and territorial ordering; monitoring and surveillance; and fostering sustainable economic activities. A recent evaluation conducted by the German Agency for International Cooperation Deutsche Gesellschaft für Internationale Zusammenarbeit (GIZ) -, the Economic Commission for Latin America and the Caribbean (ECLAC), and the Brazilian Institute for Economic Applied Research - Instituto de Pesquisa Econômica Aplicada (IPEA) - pointed monitoring and surveillance as the most effective strategy that contributed so far to the success of the plan, although under the land tenure and territorial ordering the creation of protected areas was also very relevant. The sustainable economic activities were presented in that evaluation as the most prominent need for political and financial investments. 
In August 2008 a strategy that definitely contributed to position Brazil as a proponent on the forests issue in the UNFCCC was the creation of the Amazon Fund, with strong action by the MMA and civil society. The fund is the pioneer national payment-for-performance scheme for reduction of deforestation. The Brazilian Development Bank - Banco Nacional de Desenvolvimento Econômico $e$ Social (BNDES) - is the managing institution. The Fund has a Scientific Committee that certifies the emissions reductions and an Orienting Committee that defines criteria for investments, with representatives from various ministries, states, civil society, academia, and indigenous peoples. The choice of a national institution (BNDES) over traditional international finance institutions such as the World Bank or the Global Environmental Fund (GEF) is another indicator of the search for protagonism in the forest agenda.

An innovative and simple mechanism was designed to determine the amounts that can be received each year. The fund uses the 10-year average deforestation rate as its baseline. Each year the deforestation rate is compared to that average, and emissions below that baseline will indicate how much money the fund can invest. The baseline is reviewed every five years, so from 2011 to 2015 yearly deforestation rates will be compared to the average from 2001 to 2010 (MMA 2008). The resources in the fund are donations that do not generate marketable carbon credits. The price established for each $\mathrm{CO}_{2}$ ton reduced is US\$ 5. So far the donors are Norway (US\$ 94 million), Germany (US\$ 4 million), and Petrobrás (US $\$ 4$ million). By July 2012, the Fund had already approved 32 projects out of 89, committing around US\$ 145 million (Amazon Fund 2012).

The Amazon Fund is relevant as it materializes the kind of mechanism Brazil proposed in 2006 in the domestic level. As such, the initiative is independent from REDD+ discussions in the UNFCCC, but strengthens Brazilian soft power on discussions since it is a pioneering REDD+ practical experience with an efficient and clear strategy, backed by a sound monitoring system. The partnership with Norway is strategic, since the country is the biggest donor for REDD+ and therefore a crucial player on the design of REDD+ strategies.

In 2008 Brazil also launched its National Climate Change Plan at COP-14 in Poznan. This plan includes specific commitments related to forests: reducing deforestation in $80 \%$ by 2020 and eliminating net forest loss by 2015 by incrementing the area of planted forests from 5.5 million hectares to 11 million hectares, out of which 2 million hectares from native forests. This plan is an important landmark as it is the first time Brazil takes on quantified emission reduction commitments of reducing deforestation, even though they are voluntary. Those voluntary targets were officially communicated to the UNFCCC in February 2010 through a letter to the Copenhagen Accord.

Governance over deforestation was effectively used as a power resource by the MMA in the internal negotiations that took place in 2009 and culminated in quantified voluntary commitments to be announced in Copenhagen by 
President Luís Inácio Lula da Silva. The former Minister of the Environment, Carlos Minc, had an important role of strengthening and consolidating the previous achievements of former Minister Marina Silva. Her resignation opened a unique opportunity for the MMA to negotiate with the President a new stance on climate change issues that created the favorable circumstances for launching both the National Plan on Climate Change and the voluntary targets. By then the media also started to announce the presidential candidacy of Marina Silva, which was also a decisive factor for the government to reaffirm its commitment to the environmental agenda.

As Abranches (2010) notices, taking on such commitments was not an easy decision. The MRE was against them, as was also the Civil House Minister, Dilma Rousseff. The MCT was divided, with the National Institute for Space Research and its scientists supporting them and the Climate Change Coordination against them. The Ministry of Agriculture, Livestock and Food Supply - Ministério da Agricultura, Pecuária e Abastecimento (MAPA) - supported the commitments, which was a surprise. After four meetings the MMA was able to convince the President that Brazil would be isolated in Copenhagen with its outdated position and that it was the time for the country to lead. In December the targets were announced and the traditional Brazilian position of denying any quantified commitments was abandoned.

The MMA made an important movement to present an estimate of GHG emissions by economy sectors in October 2009. Brazil presented its first National Communication in 2002 with 1994 data, and the second would only be presented in 2010. The MCT declared that those were not official numbers (Abranches 2010). That forced it to review its strategy of taking as much time as possible to submit its second National Communication to the UNFCCC, so the Ministry presented official numbers in a preliminary document to serve as a basis for the definition of the voluntary commitments.

Although the calculations that led to the numbers $36.1 \%$ to $38.9 \%$ from business-as-usual by 2020 have problems, as points Abranches (2010), Brazil demonstrated its political weight in the climate change regime. The drop in deforestation rates created the conditions for the country to adopt a proactive position that includes the willingness to transfer technologies, experience, and strategies with other tropical forest countries. This position is coherent with one of the big goals of Brazil in external relations: becoming a South leadership.

But Brazil still resists market mechanisms at the international level, which some internal as well as international actors perceive as opportunities. Therefore, the Brazilian leadership on the climate change regime has not yet been fully accomplished. The fundamental requirement for becoming a leader is being supported by others with similar views and this has not happened in the case of Brazil and the issue of forests, although the country has great influence in negotiations. And more than international support, Brazil needs to build internal 
consensus on forests and the national interest among domestic stakeholders. This has always been a complex and challenging task.

The growing involvement of non-traditional actors in international policy

Presidential Diplomacy, or the involvement of the President in international matters, is not something new in Brazil. It has been increasing since the 1980s, after the external debt crisis. Since then there is growing pressure for the integration of developing countries to the international dynamics. The first president to adopt this tendency was Fernando Collor de Mello (1990-1992). After him both Fernando Henrique Cardoso (1995-2002) and Luís Inácio Lula da Silva (2003-2010) have made a strategic investment in communicating the change in the Brazilian economic model of substituting imports to an exporting economy and demonstrating Brazil's engagement to the global context of a market economy (Cason and Powers, 2009). Specially in the government Luís Inácio Lula da Silva, such investment has not been restricted solely to economic aspects, but also to the social agenda (Lima and Hirst 2005).

In the case of climate change, the influence of the President has become more intense in 2009. It was a presidential decision that created the Amazon Governors' Task Force and it was also the President who decided that the voluntary commitments would be announced in Copenhagen and inscribed in a law. Those achievements reflect a rare but crucial moment in which the MMA had more influence over the President than the MCT and MRE. However, factors other than simple political will can explain such influence. In 2009, speculations that Marina Silva would be a candidate for the presidential elections in 2010 brought environmental issues to a new level in the domestic agenda and also political platforms of candidates such as Dilma Rousseff, who was the Civil House Minister and also President Lula's party candidate. Copenhagen presented a great opportunity for the Brazilian government to reaffirm its commitment to the environmental agenda.

The involvement of civil society is also very relevant and has been the object of further study in Brazil. Since 2001 some organizations, namely SocioEnvironmental Institute - Instituto Socioambiental (ISA) -, Institute for Amazon Research - Instituto de Pesquisa Ambiental da Amazônia (IPAM) -, and its international counterpart Environmental Defense Fund (EDF) started advocating for the inclusion of standing forests in the climate change regime in side events as well as publishing scientific articles that demonstrated the contribution of deforestation to climate change. In 2003 ISA and IPAM presented a proposal of international compensation for reducing deforestation to Minister Marina Silva which remained unanswered. In COP-9 (Milan, 2003) those NGOs organized a side event in which both the MMA (then represented by its Executive Secretary Cláudio Langone) and Greenpeace, one of the most influential NGOs in UNFCCC 
and with a strong anti-market position, were invited to share their views on the proposal. In 2004 there was a meeting in the MRE when representatives communicated that the government was willing to discuss the civil society proposal (Márcio Santilli, personal communication, 2010). In 2005 an updated version of the civil society proposal was presented, then called Compensated Reduction of Emissions from Deforestation (IPAM and EDF 2005).

The rationale of the civil society proposal was that countries that opted for reducing national emissions from deforestation in a commitment period of five years, from a historical baseline measured by satellite monitoring, would be entitled to carbon credits similar to CDM certified emission reductions. Once compensated, those countries would maintain or deepen such commitments since Annex I countries fulfilled their obligations. Some of the proposed elements were incorporated in the 2006 Brazilian proposal and the Amazon Fund, such as the historical baseline and the periodic renewal of reduction of deforestation commitments. The market component was not incorporated as it was against one of the traditional pillars of the Brazilian position: maintaining the environmental integrity of the regime.

Other relevant initiative from civil society that influenced the Brazilian government was the National Pact for Valuing Forests and Ending Deforestation, proposed by nine $\mathrm{NGOs}^{9}$ in October 2007 with the aim of establishing a commitment among various sectors to end deforestation in seven years. This proposal was considered radical by some sectors because it encompassed even the deforestation allowed by Brazilian legislation. This pact has become the basis for a discussion with BNDES on how to capture private, domestic and international resources to fund the mechanism proposed. This initiative has gathered international support, mainly by Norwegian NGOs that were already discussing the support of the Norwegian government towards efforts of tropical countries to reduce emissions from deforestation. Those discussions were the embryo of the Norwegian commitment of donating US\$ 1 billion over seven years to the Amazon Fund (Ramos 2009). As envisaged by NGOs, BNDES was designated as the manager of the Fund, whose thematic priorities are similar to the ones in the Pact proposal.

Another interesting development in 2009 is the formation of a coalition by the Amazon State Governors to propose recommendations to the Brazilian position for Copenhagen. They also proposed the creation of a specific agency connected to the Presidency to design a national system of emissions reductions (Força Tarefa sobre REDD e Mudanças Climáticas 2009). Although its demands were not fully accepted for being too market-oriented, the movement by the Governors brought part of their views to the Brazilian position, achieving a commitment that

9 ISA, Greenpeace, ICV, IPAM, The Nature Conservancy, Conservation International, Friends of the Earth Brazilian Amazon, Imazon and WWF-Brasil. 
market mechanisms would be accepted if stronger targets were adopted by Annex I countries. It is interesting to note that the report was finished in November 2009, when it was already expected that no targets would come out of Copenhagen. The involvement of subnational governments in international policymaking is still minor in Brazil, although it has been growing mostly in environmental matters.

Private sector coalitions, although very general and punctual, also influenced the Brazilian position as they showed the willingness of a strong sector to internalize climate change in decision-making and investments. Viola (2010) has analyzed three business coalitions formed between June and September 2009 to influence the Brazilian position for Copenhagen and all of them demanded the inclusion of REDD+ offsets in carbon markets.

\section{Conclusions}

The international climate change regime is presently the most relevant locus for international forest policy discussions

As demonstrated, the issue of international protection of forests is a controversial matter of international relations. Although the need for conservation of those ecosystems is virtually acknowledged, multilateralism has not been able to generate a regime that establishes principles and standards for cooperation towards that end.

Besides important achievements, deforestation is still a threat to environmental services at the local, regional, national, and global levels. Most existing instruments on forests are non-binding and are products of discussions that lack both objectivity and mandate to deal with the causes of deforestation. It is clear that countries resist to tackle deforestation at the level of international cooperation; however, due to the growing interest of society in this matter, countries need to demonstrate their willingness to reverse the global loss of forest cover, so they stay engaged in processes and institutions such as the UNFF. Voluntary agreements and hollow institution used to be the preferred options for general forest discussions.

The article also explained how the international debate on forests has been changing since Eco-92 from a legal perspective that focused on sovereignty over natural resources to an economic perspective focused on the environmental services that forests provide. Since 1995, when the first COP of the UNFCCC took place, one of these services - carbon retention - has received more attention from the international community due to its economic value and the possibility of its insertion in a market system. During the discussions to establish the rules of the Kyoto Protocol, some Latin American countries formed a coalition that aimed at including native forests in the CDM based on their contribution to biodiversity conservation. This legitimate environmental demand is connected to expectations of finance flows. Such expectations of new and additional resources to traditional 
Official Development Assistance (ODA) found new momentum in REDD+ discussions and explain why the climate change regime has emerged as the most relevant forum for international discussions on forests. It is a complex and delicate situation, since the issue of forests encompasses broader political demands than payment for services of carbon retention. Those demands, the expectations on finance, and the political priority of forest discussions brought other stakeholders to the climate change convention, such as Brazilian and international NGOs connected to the forest agenda and indigenous peoples and local communities.

Tropical deforestation represents about $17 \%$ of total global GHG emissions (IPCC 2007), which is significant. However, the overestimated potential of this solution and the underestimated importance given by some countries to domestic GHG reductions reflect broader conflicts within the climate change regime. Inserting native forests on the climate change regime is much more than just adopting mitigation actions. There are political, social and environmental consequences that are far from simple and easy. Regimes should function as living organisms in constant evolution, adapting to stimuli constantly presented by society. The outcome of those discussions will define new paths for international forest policy. It cannot be expected that the climate change regime will solve all issues at stake in the forest quasi-regime, but it should respond to demands in its sphere of competence.

\section{In international discussions on forests and climate change from 1997 to 2012 , the Brazilian position has evolved from veto to proposition}

The article mapped the evolution of the Brazilian position, which had a turning point in 2006. It is important to highlight that the transition is not yet completed and that some dissonance remains between the willingness to take on commitments, their domestic implementation, the real benefits to the Brazilian society, and the diverging reactions from different government agencies. Brazil has been influential at the international level, but its 2006 proposal to the UNFCCC has not become the preferred one among tropical forest countries. It can be concluded that such evolution of the Brazilian position is a first step to a leadership position on forests that depends on the effective solution of the issues pointed out above.

As discussed, the landmark of the evolution of the Brazilian position is the 2006 proposal to the UNFCCC of a global fund for positive incentives for reducing deforestation. The construction of such proposal is extremely interesting for various reasons. The first one is the determinant influence of civil society, which in 2003 presented to the world a view that was different from the "official" one. This caused the Brazilian federal government to try to accommodate that view - mostly the MRE, traditionally protected by its legal competence to define the national interest in international negotiations. 
The other bodies responsible for forming the Brazilian position reacted differently at the stimulus from civil society. The MMA, whose competence is to formulate the national policy on forests, acknowledged the specificities of the issue and keeps pursuing the integration of mitigation mechanisms and domestic governance over deforestation. During 2008 both MCT and MRE kept the position that REDD+ was part of the broader mitigation package and not something to be discussed separately from other issues. The interest of the MMA in discussing specific details of REDD+, such as benefit-sharing, can be explained by its proximity to other stakeholders such as civil society, state governments, and forest peoples, which is not the case of the other ministries involved. It is important to mention that the MRE and MCT have been close-following all REDD+ negotiations with MMA, but with a much more cautious perspective.

Although various NGOs and government representatives do agree that the Brazilian position has evolved; some point out that the core of that position, which is the preoccupation with the environmental integrity of the mitigation system of the UNFCCC, has not changed. The non-acceptance of offsetting or compensating fossil fuel emissions with the maintenance or enhancement of standing forests remains as the most controversial point of view of that position.

For Márcio Santilli (personal communication, 2010), the change is very small. There is a political result compared to the defensive position of 1997, but the resources the country could have received for forest protection were never received. "Nobody is paying that bill." Some international discussions on the issue of compensation through carbon markets took place within the Amazon Governors Task Force in 2009 and the synthesis report from this group mentions no ideological objection for the inclusion of REDD+ as a market mechanism. However, that inclusion was connected with the achievement of broader commitments by developed countries, so it was never presented internationally. State governments within the Amazon keep involved in discussions and agreements with other regional initiatives, such as the California system.

There is no doubt that since 2006 Brazil has gained political weight in climate change and forests negotiations. The country's position is backed by a legal and institutional framework that has been designed since 2008 with the Amazon Fund and the National Climate Change Plan, and in 2009 with the launching of the voluntary quantified emission reduction commitments inscribed in a national law. Those relevant achievements allow Brazil to share lessons, knowledge and experiences with other countries and somehow influence the Coalition for Rainforest Nations and other G-77 and China countries. However, the lack of consensus regarding market mechanisms remains as a challenge for Brazilian leadership in negotiations.

Although the 2009 law strongly emphasizes the voluntary nature of the Brazilian commitments, the new standing of Brazil on forests and climate change is a victory of Brazilian society. Climate change has become a relevant political 
issue, although still minor, in the electoral dynamics of 2010. At some point the international negotiating position, still close to China and India with a focus on the historical responsibility of developing countries and the absolute need for transfer of financial resources, will change to reflect the national political developments as wants most part of the Brazilian society. The involvement of various sectors in the discussions regarding the recent reform of the Forest Code and the campaign for the President to veto what could mean more deforestation is a clear example of the importance of the issue of forests in the national political agenda. This will eventually be reflected internationally. Brazil has gone a long way. What is needed now is implementing this sophisticated framework, next phase to be completed for the country to get closer to international leadership on climate change negotiations.

\section{On the transition from veto to proposition of alternatives on international climate change and forests negotiations, Brazil has been using its forests as soft power resources}

The shift in the Brazilian position is somehow a response to international circumstances since 2003, when efforts from various actors to include native forests in the international climate change regime started. But the domestic context was the determinant factor, as demonstrated. Since 2005 a mosaic of variables has been creating a favorable environment for Brazil to use forests as soft power resources instead of viewing them as a burden. Again, the transition is not completed although it is unlikely that it will be reversed. Those domestic variables are governance over deforestation; the growing participation of the Presidency on climate change policy both internationally and domestically; the emergence of the MMA as a relevant actor in climate change discussions; and the growing interest of domestic actors not traditionally connected to international environmental negotiations, such as Amazon governors and the private sector, which effectively brought their views to the table.

From the picture drawn above, two variables clearly demonstrate the use of forests as soft power resources. The first is governance over deforestation. The positive results achieved by PPCDAM, coupled with market factors such as price changes and the growing demand for environmental compliance of productive chains, have made Brazil successfully deal with its major vulnerability on international forests discussions: the alarming rates of deforestation in the Amazon. Of the strategies in PPCDAM, one deserves special mention: improvement of satellite monitoring. All information is now publicized on the internet, which is a major development in terms of transparency. Brazil has become a global reference due to its satellite monitoring systems and this knowledge is gradually becoming an important area of south-south cooperation. This is a clear demonstration of Brazil using forests as soft power resources. 
The second variable is the emergence of the MMA as a relevant actor in climate change discussions due to the reversal in the high deforestation rates. In 2003 this reduction was defined as a priority by Minister Marina Silva, who successfully involved other ministries with agendas not directly connected to environmental protection but whose sectoral agendas deal with deforestation drivers such as agriculture and livestock, public finance, infrastructure, etc. The Ministry of the Environment was able to build domestic strategic alliances, for example, with the National Institute for Space Research and BNDES, and achieved a victory on something that Brazil was ashamed of before international society. Marina Silva's resignation opened a strategic political window for the launching of previously agreed instruments: the Amazon Fund, the National Plan, and the National Policy on Climate Change. Although the Plan is heavily criticized for being a collection of actions already defined and budgeted for, this instrument for the first time defined a target for reducing deforestation, which is a historical achievement for the country.

It should be highlighted that forests are more than carbon sinks: they harbor a significant share of the world's biodiversity; they are home to forest peoples and have a fundamental role in water cycles and protection of soils. A strictu sensu market mechanism that will treat forest carbon as any commodity and will seek maximizing profits and minimizing costs will not be able to contribute to reversing neither global climate change nor the destruction of forests if those specificities are not considered.

Forests are part of the problem and part of the solution for global climate change. Brazil, the biggest tropical forest country, has demonstrated its capacity to use forests as soft power resource in the climate change regime. This achievement is a valuable learning for its action in other environmental forums and agendas, which should be object of continuous improvement.

\section{Bibliographic references}

ABDALLA, Fabio. Governança Global sobre Florestas: o Caso do Programa Piloto para Proteção das Florestas Tropicais do Brasil-PPG7 (1992-2006). Doctoral Thesis, Brasília, UNB, International Relations Institute, 2007.

ABRANCHES, Sérgio. Copenhague: Antes e Depois. Rio de Janeiro: Civilização Brasileira, 2010.

Allison, Graham T. Conceptual Models and the Cuban Missile Crisis. The American Political Science Review, Vol. 63, No. 3. Sept. 1969.

BÄCKSTRAND, Karin e LÖVBRAND, Eva. Planting Trees to Mitigate Climate Change: Contested Discourses of Ecological Modernization, Green Governmentality and Civic Environmentalism. Global Environmental Politics 6:1, MIT: Massachusetts, 2006.

BRASIL. Presidência da República. Plano de Ação para a Prevenção e Controle do Desmatamento na Amazônia Legal, 2004. 
BRASIL. Presidência da República. Plano de Ação para a Prevenção e Controle do Desmatamento na Amazônia Legal, 2010.

BRUNNENGRÄBER, Achim. The Political Economy of the Kyoto Protocol. Socialist Register, 2007. CASON, Jeffrey W. and POWER, Timothy J. Presidentialization, Pluralization, and the Rollback of Itamaraty: Explaining Change in Brazilian Foreign Policy Making in the Cardoso-Lula Era. International Political Science Review 2009; 30.

CHASEK et al. Global Environmental Politics. Westview: Boulder, 2006. $4^{\mathrm{a}} \mathrm{ed}$.

CONNIFF, Richard. The Political History of Cap-and-Trade. Smithsonian Magazine, August 2009. Available at <http://www.smithsonianmag.com/sciencenature/Presence-of-Mind-BlueSky-Thinking.html>.

DIMITROV, Radoslav. Hostage to Norms: States, Institutions and Global Forest Politics. Global Environmental Politics 5:4. MIT: Massachusetts, 2005.

FRIBERG, Lars. Varieties of Carbon Governance: The Clean Development Mechanism in Brazil-a Success Story Challenged. The Journal of Environment Development 2009; 18.

GULBRANDSEN, Lars H. Overlapping Public and Private Governance: Can Forest Certification Fill the Gaps of the Global Forest Regime? Global Environmental Politics 4:2. MIT: Massachusetts, 2004.

HUMPHREYS, David. Logjam: Deforestation and the Crisis of Global Governance. Earthscan: London, 2006.

IPCC. Fourth Assessment Report, 2007.

KRASNER, Stephen D. International Regimes. Cornell International University, 1983.

KEOHANE and NYE. Power and Interdependence. Longman Classics in Political Science, 2001, 3rd ed.

PUTNAM, Robert. D. Diplomacy and Domestic Politics: The logic of two-level games. International Organization, Vol. 42, No. 3, 1988.

RAMOS, Adriana. Articulação Nacional contra o Desmatamento. Democracia Viva, no 41. IBASE, janeiro de 2009.

Relatório da Força-Tarefa dos Governadores da Amazônia, 2009.

SANTILLI et al. Tropical Deforestation and the Kyoto Protocol: an Editorial Essay. In Moutinho, Paulo e Schwartzman, Steve. Tropical Deforestation and Climate Change. IPAM and EDF, 2005.

SPRINZ, Detlef et al. International Nonregimes: A Research Agenda. InternationalStudiesReview 9 (2): 230-258, 2007.

VIOLA, Eduardo. Impasses e Perspectivas da Negociação Climática Global e Mudanças na Posição Brasileira. Brasília: Cindes, 2010.

YOUNG, Oran. The Effectiveness of International Regimes: Causal Connections and Behavioural Mechanisms. MIT Press, 1999. 


\begin{abstract}
This articledescribes the Brazilian position on forests and climatechangefrom 1997 to 2012. Itargues that it has evolved from a veto, which excluded from the climate change regimeemissions from the conversion of native forests, to a proposition, as Brazil offered its approach to the international community. It explains the change with domestic developments: governance over deforestation, the emergence of new and relevant actors, and presidential diplomacy.
\end{abstract}

Keywords: Brazilian environmental policy; climate change; forests.

\title{
Resumo
}

Este artigo descreve a posição brasileira sobre as florestas e sobre mudança climática de 1997 a 2012. Tem-se como argumento que isso evoluiu de um veto, que excluía do regime de mudança climática as emissões por conversão de florestas nativas, para uma proposição, enquanto o Brasil oferecia sua abordagem à comunidade internacional. O artigo explica essa mudança a partir de desenvolvimentos domésticos: governança sob desmatamento, a emergência de novos e relevantes atores, e a diplomacia presidencial.

Palavras-chave: política ambiental brasileira; mudança climática; florestas. 